\title{
Corpus Callosum Deficiency in Transgenic Mice Expressing a Truncated Ephrin-A Receptor
}

\author{
Zhaoliang Hu, ${ }^{1,3}$ Xin Yue, ${ }^{1,3}$ Guanfang Shi, ${ }^{1,3}$ Yong Yue, ${ }^{1,3}$ David P. Crockett, ${ }^{3}$ Jan Blair-Flynn, ${ }^{4}$ Kenneth Reuhl, ${ }^{2}$ \\ Lino Tessarollo, ${ }^{4}$ and Renping Zhou ${ }^{1,3}$ \\ ${ }^{1}$ Laboratory for Cancer Research and ${ }^{2}$ Department of Pharmacology, College of Pharmacy, Rutgers University, and ${ }^{3}$ Department of Neuroscience and Cell \\ Biology, Robert Wood Johnson Medical School, Piscataway, New Jersey 08854, and ${ }^{4}$ Neural Development Group, Mouse Cancer Genetics Program, National \\ Cancer Institute-Frederick Cancer Research and Development Center, Frederick, Maryland 21701
}

The A-class of the erythropoietin-producing hepatocellular carcinoma cell-derived (EphA) tyrosine kinase receptors and their ligands, the A-ephrins, play critical roles in the specification of topographic axon projection maps during development. In this study, the role of the EphA subfamily in callosal projections was investigated using transgenic mice expressing a kinase deletion mutant of EphA5. In approximately half of these transgenic mice, cerebral cortical neurons in various cortical regions (primary and secondary somatosensory cortices and frontal as well as visual areas) failed to project to the contralateral cortex. When commissural axons were examined with DiI labeling, few callosal fibers were found to traverse the midline in both the adult and neonatal transgenic mice. This defect in callosal development correlates with the expression of the transgene, because neurons in the superficial layers of the motor cortex, where transgene expression is low, show normal contralateral projection through the corpus callosum. In addition, multiple EphA receptors are expressed in callosal neurons and ephrin-A5 stimulates neurite outgrowth of callosal neurons in vitro. The midline glia structures important for callosal axon midline crossing appear normal in the transgenic mice, suggesting that the defects are unrelated to defective guidance structures at the midline. These observations suggest critical functions for EphA receptor in establishing callosal connections during brain development.

Key words: corpus callosum; axon guidance; Eph receptors; ephrins; transgenic mice; neurite outgrowth

\section{Introduction}

Contralateral cerebral cortical projections through the corpus callosum integrate sensory and motor performance of the two brain hemispheres. In "split-brain" animals and individuals whose corpus callosum have been severed, interhemispheric transfer of sensory and motor information is deficient (Gazzaniga, 1995). In these individuals, visual and tactile information presented to one hemisphere is not available for analysis by the other hemisphere. In addition, perceptual interactions between the two hemispheres are absent in these individuals. These observations, pioneered by Roger Sperry in the 1960s (Sperry, 1968, 1982), defined the critical roles of contralateral cortical projections in human consciousness and behavior.

Anatomical studies in a wide variety of animals revealed that a large proportion of the contralateral projection (callosal) neurons are located in layers $2 / 3$ and 5 (Innocenti, 1984). Callosal axons project mostly to corresponding, homotopic areas of the contralateral cortex. During the development of callosal projec-

Received Aug. 20, 2003; revised Sept. 26, 2003; accepted Sept. 26, 2003.

This research was supported in part by grants from the National Institutes of Health, the National Science Foundation, and the New Jersey Governor's Council on autism to R.Z. We thank M. David Egger and Ping Chao for assistance in imaging and statistical analysis, and Linda Richards for critical comments on this manuscript.

Correspondence should be addressed to Dr. Renping Zhou, Laboratory for Cancer Research, College of Pharmacy, Rutgers University, Piscataway, NJ 08854. E-mail: rzhou@rci.rutgers.edu.

Y. Yue's present address: CNS Disease Department, Aventis Pharmaceuticals, Bridgewater, NJ 08807. Copyright $\odot 2003$ Society for Neuroscience $\quad$ 0270-6474/03/2310963-08\$15.00/0 tions, a number of decisions have to be made by the axons. In the mouse, callosal axons must first find their way to the cortical white matter and then turn medially, cross the midline, and then reenter appropriate contralateral cortical areas to form synapses with the target neurons. Disruptions at any of these critical choice points will likely lead to pathfinding and targeting errors.

Although the corpus callosum is critical for information transfer between the two hemispheres, the mechanisms guiding the development of this fiber system are not well understood. Previously it has been shown that the erythropoietin-producing hepatocellular carcinoma cell-derived A5 (EphA5), a member of the large Eph family of tyrosine kinase receptors, is expressed in the cortical layers 2/3 and 5 (Zhang et al., 1997), where most of the callosal neurons reside. The expression of EphA5 in these cortical layers raises the possibility that EphA receptors may function to guide callosal axons, because a prominent function of the Eph family is axon guidance (Flanagan and Vanderhaeghen, 1998; Zhou, 1998; Dodelet and Pasquale, 2000; Wilkinson, 2000; Kullander and Klein, 2002). Consistent with this notion, EphB2 and EphB3 have been shown previously to be important for the development of the anterior commissure and the corpus callosum (Henkemeyer et al., 1996; Orioli et al., 1996). To determine whether EphA receptors also contribute to the development of the corpus callosum, we examined transgenic mice carrying a mutated form of the receptor EphA5, EphA5 $(\mathrm{K}-)$, generated previously (Yue et al., 2002). The mutant receptor contains the 
ligand-binding and transmembrane domains of EphA5, but the intracellular kinase domain has been replaced with an enhanced green fluorescence protein (eGFP). This truncated receptor inhibits the activity of the wild-type EphA receptors and therefore interferes with the function of the endogenous EphA receptors (Yue et al., 2002). In EphA5(K-) transgenic mice, medial hippocampal axons terminate more ventrally compared with the wild type, indicating a critical function of the EphA receptors and ligands in topographic mapping of hippocampal axon terminals (Yue et al., 2002). Here we report that in approximately half of these mice, the contralateral cerebral cortical projection is also deficient. Callosal axons show reduced growth toward the callosal axon tract and the midline, revealing a new function of the EphA receptors in the development of axon pathways.

\section{Materials and Methods}

Transgenic mice. EphA5(K-) transgenic mice were generated in C57BL/6J $\mathrm{X} \mathrm{C} 3 \mathrm{H} / \mathrm{HeJ}$ F1 background as described previously (Yue et al., 2002). These mice express a truncated EphA5 receptor [EphA5(K-)] fused to eGFP under the transcriptional control of a neuron-specific $\alpha$-tubulin promoter. The transgene retains the extracellular and transmembrane domains but lacks the intracellular domain of EphA5 receptor. Two independent lines of mice (Ag30-61 and Ag0072) were analyzed, and both yielded similar results. Mice with higher copy numbers of the transgene were identified using PCR as well as Southern blot analysis as described (Yue et al., 2002). Two different controls have been used in this analysis: (1) wild-type nontransgenic (C57BL/6J X C3H/HeJ) F1 mice bred in parallel to the transgenic animals and (2) transgenic mice expressing only the eGFP in the same construct. Both of these two control strains show normal corpus callosum development.

In situ hybridization. Localization of transcripts encoding the EphA5(K-) transgene was performed by using in situ hybridization methods as described (Zhang et al., 1997). An antisense GFP riboprobe was used to detect transgene expression, and the corresponding sense probe was used for control as described previously (Yue et al., 2002).

Tissue preparation and histological analysis. Animals were anesthetized with ketamine $\mathrm{HCl} / \mathrm{xylazine} \mathrm{HCl}$ solution $(50 \mathrm{mg} / \mathrm{kg}$, i.p.) and perfused transcardially with saline, followed by $4 \%$ paraformaldehyde (PFA) in $0.1 \mathrm{~m}$ phosphate buffer, $\mathrm{pH}$ 7.4. Brains were removed and postfixed in the same fixative for $2-3 \mathrm{hr}$. The tissues were dehydrated in graded ethanol solutions, cleared in xylene, and embedded in paraffin. Coronal sections $(5 \mu \mathrm{m})$ were cut and mounted on polylysine-coated slides. Sections were stained with thionin or hematoxylin and eosin. The thickness of the cerebral cortex in area S1 and the corpus callosum at the midline were measured in five wild-type and five EphA5(K-) transgenic mice, using Image-pro plus imaging software. Five coronal sections of $20 \mu \mathrm{m}$ apart spanning $\mathrm{S} 1$ were quantified and averaged for each mouse. Statistical significance was determined using two-way ANOVA.

Fluoro-Gold and DiI tracing in adult mice. For retrograde labeling, Fluoro-Gold (4\% in saline) was injected by micro-iontophoresis (7 $\mathrm{sec}$ on/7 sec off at $0.5 \mu \mathrm{A}$ for $20 \mathrm{~min}$ ) in different cortical areas, using standard stereotaxic coordinates (Franklin and Paxinos, 1997). Animals were killed $3 \mathrm{~d}$ later and perfused with $4 \%$ PFA, and $50 \mu \mathrm{m}$ brain sections were made with a microtome. Anterograde DiI labeling was performed with fixed mouse brains. DiI solution ( $10 \%$ in $N, N$-dimethyl-formamide, $0.5-1$ $\mu \mathrm{l})$ was injected into cortex after either adult or postnatal mice were perfused with $4 \%$ PFA in PBS. After 1 month of incubation in 4\% PFA containing $30 \%$ sucrose at $37^{\circ} \mathrm{C}$, brain sections of $100 \mu \mathrm{m}$ thickness were cut with a vibratome and examined with a Zeiss Axioskope equipped with Fluoro-Gold or rhodamine filters. Quantification of retrogradely labeled callosal neurons was performed in control and in phenotypically positive brain sections only.

Glial fibrillary acidic protein immunocytochemistry. The newborn [postnatal day (P) 0] animals were anesthetized by cooling on ice over a metal plate, perfused with $4 \% \mathrm{PFA}$ in $0.5 \times \mathrm{PBS}$, and postfixed in PFA for 2-4 hr. Postfixed brains were cryoprotected in 30\% sucrose overnight and sectioned with a cryostat. After preincubation with PBS containing $2 \%$ normal goat serum and $0.25 \%$ BSA for $1 \mathrm{hr}$, the tissue sections were incubated with rabbit anti-cow glial fibrillary acidic protein (GFAP) antibody (1:1000, Dako, Glostrup, Denmark; product code Z0334) followed by Cy3-conjugated goat anti-rabbit antibody (Jackson ImmunoResearch, West Grove, PA; $1 \mu \mathrm{g} / \mathrm{ml}$ ).

Double labeling of callosal neurons with Fluoro-Gold retrograde tracing and anti-EphA receptor antibodies in early postnatal mice. The $\mathrm{P} 0$ animals were anesthetized by cooling on ice over a metal plate; Fluoro-Gold $(0.5$ $\mu \mathrm{l})$ was injected into the somatosensory cortex unilaterally. After $2 \mathrm{~d}$ of survival, the labeled pups were perfused with $4 \%$ paraformaldehyde in $0.05 \mathrm{~m}$ PBS and postfixed in the same fixative for 2-4 hr. Postfixed brains were kept in $30 \%$ sucrose overnight and sectioned with a cryostat. Preincubation was performed as described in the previous section. The tissue sections were then incubated with rabbit anti-EphA3 (c-19) and -EphA7 (k-16) antibodies (Santa Cruz Biotechnology, Santa Cruz, CA; 1 $\mu \mathrm{g} / \mathrm{ml}$ ) or human ephrin-A5/crystallizable fragment of $\operatorname{IgG}(\mathrm{Fc})$ chimera diluted in $0.5 \times$ PBS $(0.5 \mu \mathrm{g} / \mathrm{ml} ; \mathrm{R} \& \mathrm{D}$ Systems, Minneapolis, $\mathrm{MN})$ at $4^{\circ} \mathrm{C}$ overnight. After three washes of $15 \mathrm{~min}$ each with $0.5 \times$ PBS, the sections were incubated with biotinylated secondary antibodies [goat anti-rabbit for the anti-EphA antibodies (Vector Laboratories, Burlingame, CA); rabbit anti-human IgG Fc fragment for ephrin-A5-Fc (Jackson ImmunoResearch); $2.5 \mu \mathrm{g} / \mathrm{ml}$ in $0.5 \times \mathrm{PBS}$ ]. The sections were further incubated with Texas Red-conjugated egg-white avidin (Jackson ImmunoResearch; $2 \mu \mathrm{g} / \mathrm{ml}$ ). The signals were amplified further by incubating the treated sections with an additional incubation with a monoclonal antiavidin antibody (1:1000; Sigma, St. Louis, MO; catalog \#A5680), followed by a final incubation with Texas-Red-conjugated egg-white avidin. The results were observed with a Zeiss Axiovert $100 \mathrm{M}$ confocal microscope.
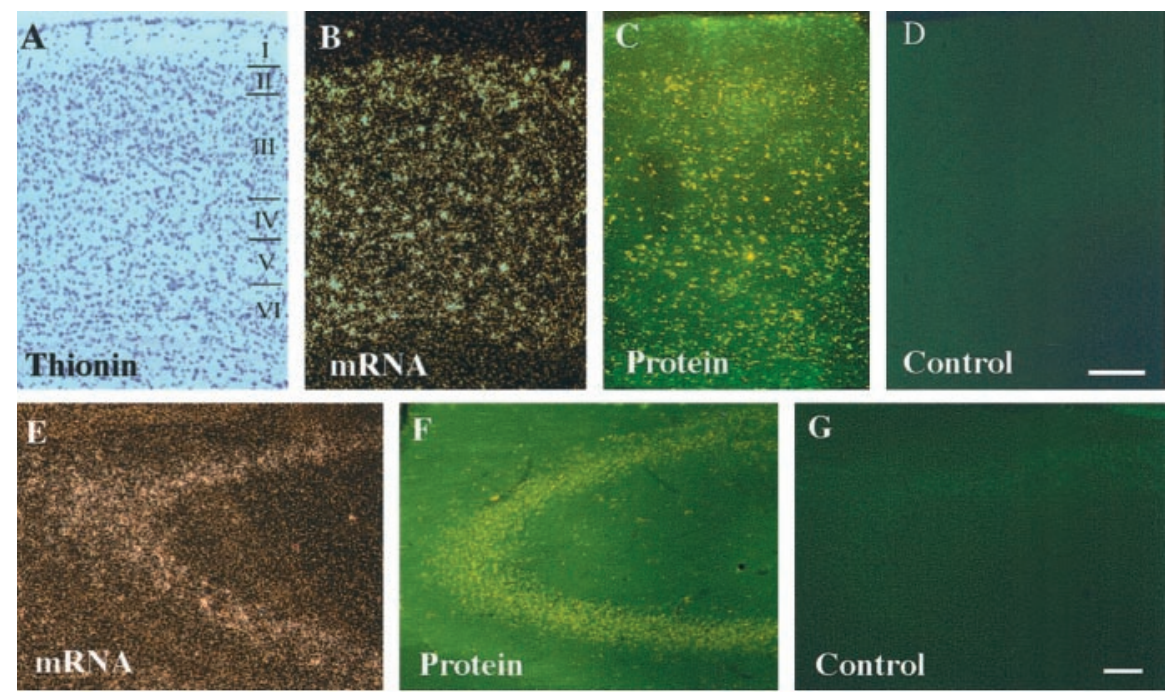

Figure 1. Expression of EphA5(K-) transgene in the cerebral cortex and hippocampus of transgenic mice. $A, A$ bright-field photomicrograph of the primary somatosensory area (S1) of a hybridized coronal section from an adult transgenic mouse brain, counterstained with thionin. $B, C$, mRNA and protein expression of EphA5(K-) transgene in $\mathrm{S} 1$ of the cerebral cortex, respectively. $D, A$ photomicrograph of the corresponding region from a nontransgenic control brain section. No specific green fluorescence was observed. $E, F$, EphA5(K-) transgene mRNA and protein expression, respectively, in the hippocampus of the transgenic mice. $G, A$ photomicrograph of the hippocampal region from a nontransgenic control mouse. mRNA expression of the transgene was detected by in situ hybridization using an antisense eGFP probe, and the fusion protein levels were examined under a fluorescence microscope. Scale bar, $100 \mu \mathrm{m}$. 
Wild type
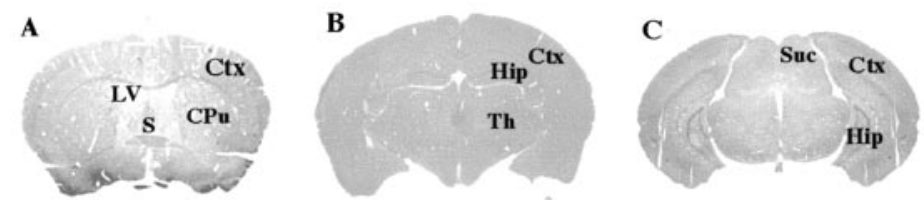

D

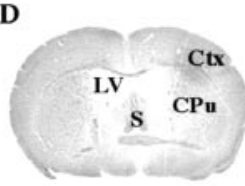

E
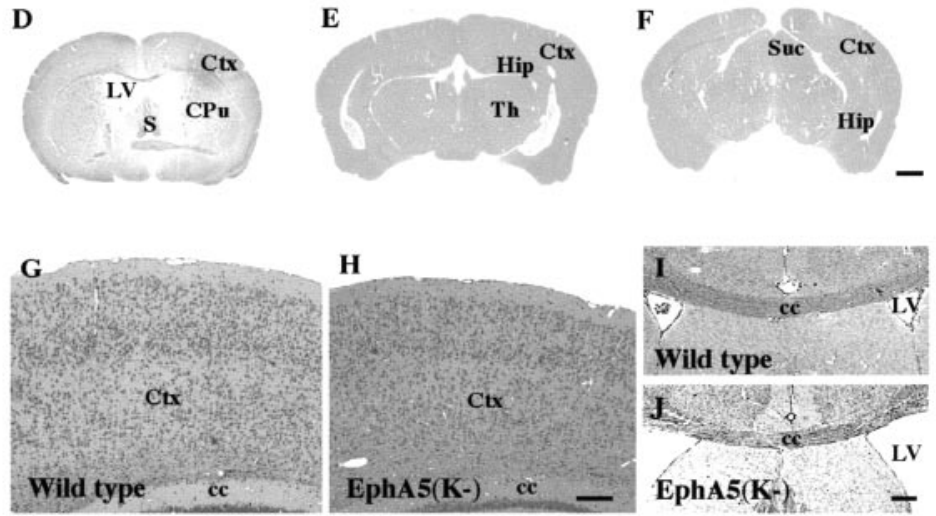

$\mathbf{H}$
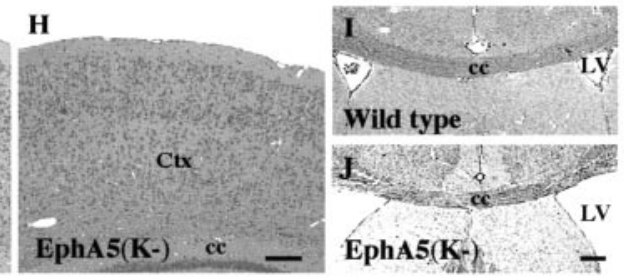

$\mathbf{K}$

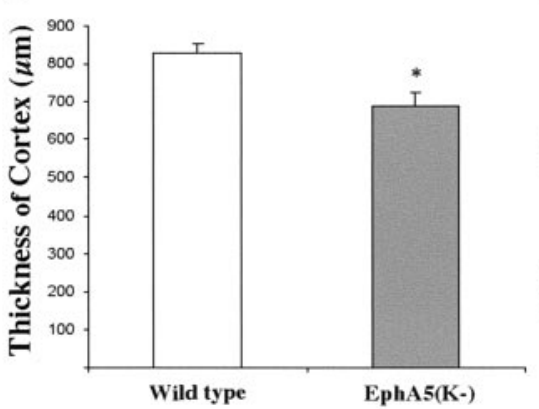

$\mathbf{L}$

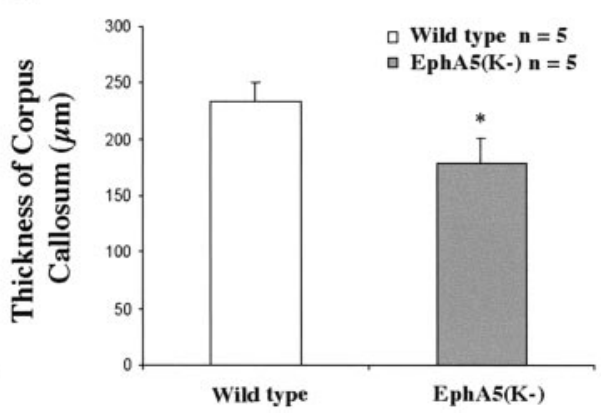

Figure 2. Morphological changes of the cerebral cortex and the corpus callosum in transgenic mice. Coronal brain sections were stained with hematoxylin and eosin. Shown are sections at the levels of the septum $(A, D)$ and anterior $(B, E)$ and posterior $(C, F)$ hippocampus. $A-C$, Wild type. $D-F$, EphA5(K-) transgenic mice. Note that the lateral ventricles of the transgenic mice are enlarged compared with wild-type control animals. $G, H$,Morphology of $S 1$ in wild-type $(G)$ and transgenic $(H)$ mice. I, J, Morphology of the corpus callosum of wild-type (I) and transgenic ( $/$ ) mice. $K$, Morphometric analysis of thickness of the cerebral cortex in area S1.L, Morphometric measurements of the thickness of corpus callosum at the midline in wild-type and transgenic mice. S, Septum; Cpu, caudate-putamen; Hip, hippocampus; Ctx, cerebral cortex; Th, thalamus; SuC, superior colliculus; cc, corpus callosum; LV, lateral ventricle. ${ }^{*} p<0.05$; two-way ANOVA. Scale bars: $F, 1 \mathrm{~mm} ; H, J, 100 \mu \mathrm{m}$.

Labeling of callosal neurons with DiI and analysis of effects of ephrin-A5 on callosal neurite outgrowth. DiI solution $(0.5 \mu \mathrm{l} ; 10 \%$ in $N, N$-dimethylformamide) was injected into the somatosensory cortex of P0 wild-type mouse pups. After $2 \mathrm{~d}$ of survival, the contralateral cortex was dissected in PBS with the aid of a microscope. Dissected tissues were dissociated by triturating with a fire-polished glass pipette to single-cell suspension and plated at a density of $5 \times 10^{5}$ cells per well in 12-well dishes preseeded with a confluent monolayer of either control NIH3T3 cells or NIH3T3 cells expressing ephrin-A5 constructed previously (Gao et al., 1998, 1999). After $24 \mathrm{hr}$, the cultures were fixed with $4 \%$ freshly prepared PFA in PBS for 8 min. The number and length of DiI-labeled callosal neurites were analyzed with a Zeiss Axioskop microscope. The experiment was repeated three times.

\section{Results}

Development of the corpus callosum is disrupted in mice expressing a truncated EphA5 receptor

To determine whether the EphA receptors might regulate development of the corpus callosum, the effects of EphA5(K-) transgene expression were analyzed. The expression of the EphA5(K-) transgene was determined using in situ hybridization with an antisense eGFP riboprobe and GFP fluorescence. High levels of transgene expression were observed in the cerebral cortex and in the hippocampus (Fig. 1). Histological analyses showed variable degrees of enlargement of the lateral ventricles in the transgenic mice (Fig. $2 A-F)$. Consistent with this observation, there were mild reductions in the thickness of both the somatosensory cortex and the corpus callosum compared with that of the wild-type mice (Fig. $2 G-J$ ). To quantify these differences, the thickness of the primary somatosensory (S1) cortex and the corpus callosum at the midline was measured. These analyses showed that both $\mathrm{S} 1$ and the corpus callosum in the transgenic mice were slightly thinner than that of the control animals (Fig. $2 K, L$ ) $(n=5)$.

To examine the effects of EphA5(K-) expression on cortical projections, Fluoro-Gold, a retrograde axon tracer, was injected into various cortical regions. When the tracer was injected in S1, numerous cortical neurons were labeled in the contralateral cortex in all of the nontransgenic wild-type mice or vector-only control transgenic mice (Fig. $3 A, E)(n=$ 26). In contrast, very few contralateral neurons were labeled in $48 \%$ of EphA5(K-) transgenic mice (15 of 31) when the tracer was similarly injected (Fig. $3 B, E)$. Quantitative analyses indicated that the most striking differences between the number of labeled contralateral neurons in wild-type control and the transgenic animals with callosal defects were found in layers 3 and 5 , where most of the callosal neurons are located (Fig. 3E). To further examine this deficiency, the lipophilic fluorescent axon tracer DiI was injected in the adult S1 to anterogradely label callosal axons. These experiments showed that callosal fibers in wild-type mice crossed the midline in a highly organized manner $(n=6)$ (Fig. 3C), whereas in transgenic mice the callosal fibers failed to traverse the midline but traveled along the longitudinal axis to form Probst bundles in the ipsilateral side near the midline (three of six transgenic mice traced) (Fig. 3D). The Probst bundles found in these mice were variable and usually small. These results suggest that the EphA receptors play important roles in guiding callosal axons across the midline during development.

\section{Callosal neurons in the medial cortex have a normal contralateral projection}

To examine how the expression of the EphA5(K-) transgene influenced the callosal projections of different neurons, FluoroGold was injected into several other brain regions including the motor cortex, the secondary somatosensory cortex (S2), the frontal cortex, and the visual cortex. These analyses showed that the motor cortex had a normal projection to the contralateral cortex $(n=4)$ (Fig. 4A-E). In contrast, callosal neurons in S2 (two of five transgenic mice analyzed), the frontal (three of seven), and visual (four of eight) cortices failed to project to the contralateral 

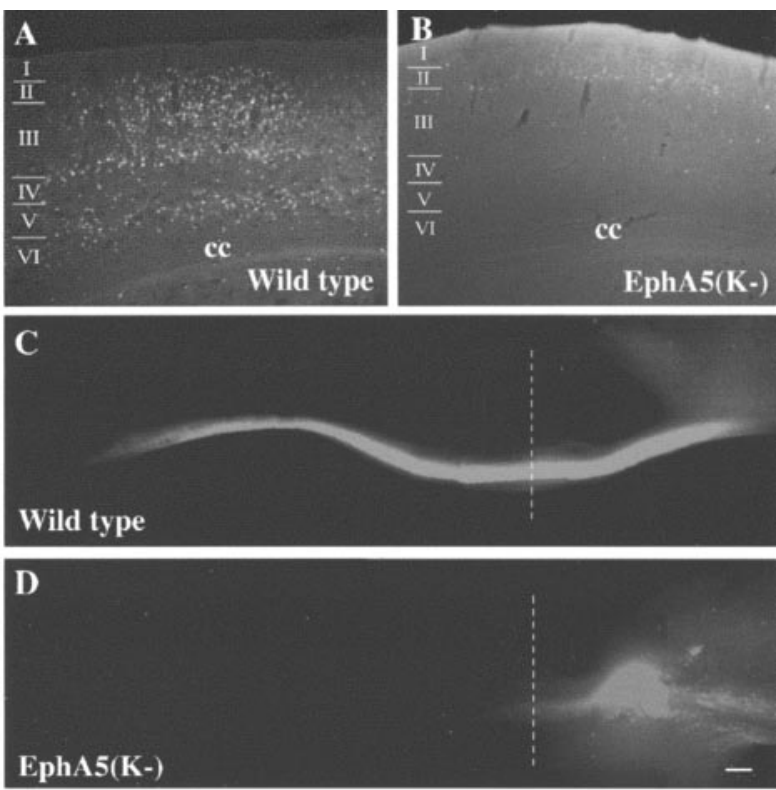

E

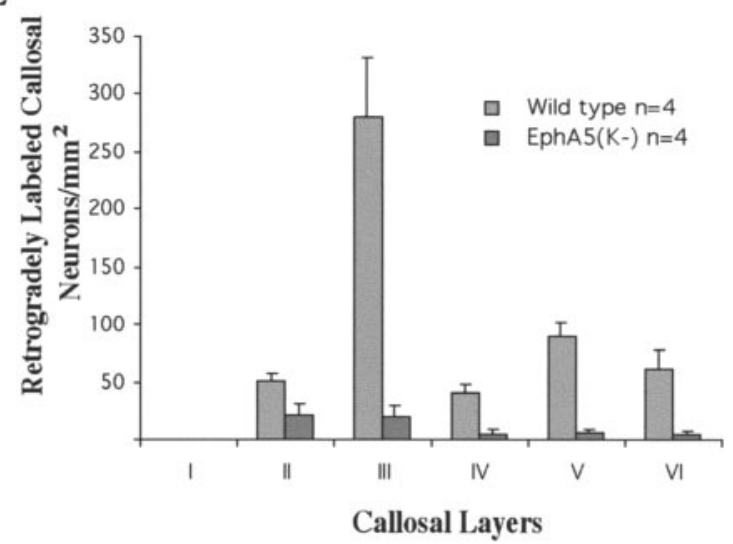

Figure 3. Callosal projection deficiency in EphA5(K-) adult transgenic mice. $A, B$, Fluoro-Gold retrograde tracing of adult wild-type $(A)$ and transgenic $(B)$ mice. The tracer was injected into the contralateral S1 region. Many more neurons were retrogradely labeled by Fluoro-Gold in wild type $(A)$ than in the transgenic contralateral cortex $(B) . C, D$, Anterograde labeling of corpus callosum with Dil in wild-type $(C$ and transgenic $(D)$ mice. Dashed lines indicate the midline. E, Quantitative analysis of the distribution of callosal neurons in different cortical layers. For transgenic mice, only brains with callosal defects were analyzed. cc, Corpus callosum. Scale bar, $100 \mu \mathrm{m}$.

cortices (Figs. 4F-J, 5). To analyze whether the differences in the contralateral projection in these different areas correlated with differences in the expression of the transgene, the levels of GFP fluorescence in these regions were examined. This analysis showed that the level of EphA5(K-) expression in callosal neurons in the motor cortex, which were located in the superficial layers, was significantly lower than in the other regions (Fig. 4, compare $E, J)$, suggesting that the callosal defects depend on the levels of expression of EphA5(K-).

\section{Callosal axons fail to cross the midline at early postnatal stages in EphA5(K-) transgenic mice}

To examine the development of the aberrant callosal projections, callosal axons were examined using DiI tracing in early postnatal (P0 and P5) EphA5(K-) mice. In wild-type animals, the corpus callosum was well formed by the day of birth and projected to the contralateral side (Fig. 6A, $B$ ). In the transgenic mice, two differ- ent phenotypes were observed. First, axons of the callosal neurons failed to grow into the corpus callosum in 4 of 13 P5 transgenic mice analyzed (Fig. 6C,D). Second, callosal fibers that reached the corpus callosum tract were still short of the midline by $\mathrm{P} 5$ in 2 of the 13 transgenic mice analyzed (Fig. $6 E, F$ ). Similar deficiencies were also found in $\mathrm{P} 0$ animals (data not shown). To examine whether the glial wedge and the indusium griseum, which have been implicated in guiding callosal axons to cross the midline (Shu and Richards, 2001), develop normally in the transgenic mice, $\mathrm{P} 0$ control and EphA5(K-) transgenic mouse brains were stained with anti-GFAP antibody. The GFAP-positive glial wedge as well as indusium griseum show normal morphology in all of the 11 EphA5(K-) transgenic mice examined (Fig. 7). This observation suggests that the projection deficiency is unlikely to be caused by a deficiency in the midline glial structures in the transgenic mice, although altered guidance properties of these structures could not be excluded.

\section{EphA receptor expression in callosal neurons}

The observation that EphA5(K-) transgene expression induces callosal axon projection defects suggests that the EphA receptors are expressed in callosal neurons and function to guide callosal axons to their contralateral targets. Several EphA receptors (EphA3-EphA7) have been shown to be expressed in the developing cerebral cortex (Taylor et al., 1994; Mori et al., 1995; Zhang et al., 1997; Donoghue and Rakic, 1999; Rogers et al., 1999); however, it is not known whether the EphA receptors are expressed specifically in callosal neurons. To examine EphA receptor expression, callosal neurons were first retrogradely labeled with Fluoro-Gold. For this purpose, Fluoro-Gold was injected into one side of the cerebral cortex (somatosensory area) of normal P0 mice, and the injected mice were allowed to survive for $2 \mathrm{~d}$ after injection. The injected animals were then perfusion-fixed, and the brain sections were stained with anti-EphA3 and EphA7 antibodies and ephrin-A5-Fc, coupled with Texas Red-labeled secondary antibody, to examine EphA receptor expression in callosal neurons. Both antibodies and ephrin-A5-Fc bind to neurons retrogradely labeled with Fluoro-Gold, although not all callosal neurons express EphA receptors (Fig. 8). Preimmune rabbit serum (Fig. 8) and anti-EphA receptor antibodies in the presence of blocking antigens gave no specific signals (data not shown). Furthermore, both anti-EphA3 and -EphA7 are highly specific, recognizing primarily the specific proteins, as shown by Western blot analysis using these two antibodies (Fig. $8 M, N$ ). These observations indicate that several EphA receptors are expressed in the callosal neurons. Similar results were obtained when callosal neurons retrogradely labeled with Fluoro-Gold were examined in dissociated cultures (data not shown).

\section{Ephrin-A5 promotes callosal neurite outgrowth}

To investigate how EphA receptors and ligands regulate callosal projections, DiI-labeled P2 callosal neurons were cocultured with stably transfected NIH3T3 cells expressing ephrin-A5 or control cells. Callosal neurons extended only short neurites in cocultures with control cells (Fig. 9A,D); however, these neurons grew longer neurites in cocultures with ephrin-A5-expressing cells (Fig. $9 B, D$ ). The percentage of callosal neurons with neurites was also significantly higher in ephrin-A5 cocultures than in control cocultures (Fig. 9C). These data indicate that ephrin-A5 promotes callosal neurite outgrowth.

\section{Discussion}

We have analyzed the effects of ecotopic expression of a truncated EphA5 receptor under the control of a neuron-specific $\alpha$-tubulin 
M1/M2
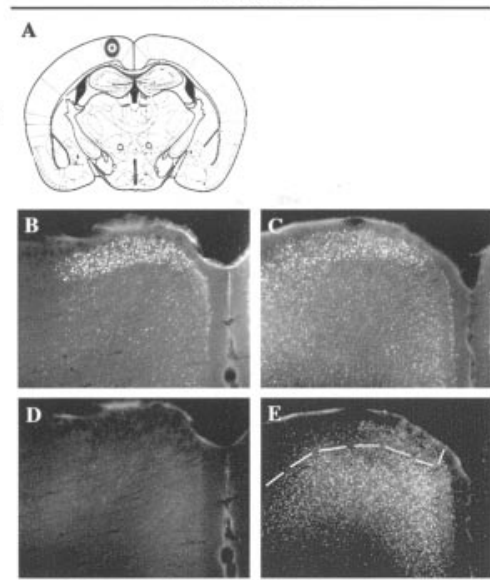

Wild type

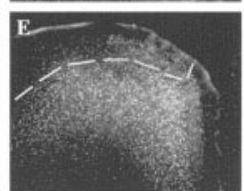

$\operatorname{EphA5(K-)~}$

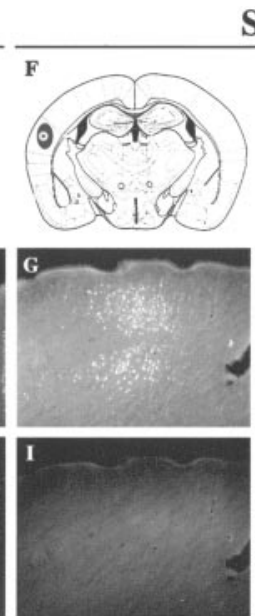

Wild type

Figure 4. Deficiency in callosal projections correlates with transgene expression. $A$, A diagram indicating Fluoro-Gold injection site in the primary and secondary motor area (M1/M2). $B, C$, Retrograde labeling of the contralateral motor cortex in wild-type ( $B)$ and transgenic ( $($ ) mice, respectively. D, E, EphA5(K-) expression in the motor cortex. No significant fluorescence was observed in wild-type nontransgenic control mice $(D)$. In EphA5(K-) transgenic motor cortex $(E)$, the expression in the superficial layers (delineated by the dotted line), where callosal neurons are located, is low compared with other cortical areas where callosal defects were observed (compare $E, J)$. F, A diagram showing Fluo-Gold injection site in secondary somatosensory cortex (S2). $G, H$ Contralateral Fluoro-Gold labeling of callosal neurons in S2 of wild-type $(G)$ and transgenic $(H)$ mice. I, J, Expression of EphA5(K-) transgene protein in $\$ 2$ of wild-type control ( $/$ ) and transgenic ( $/$ ) mice. Scale bar, $100 \mu \mathrm{m}$.

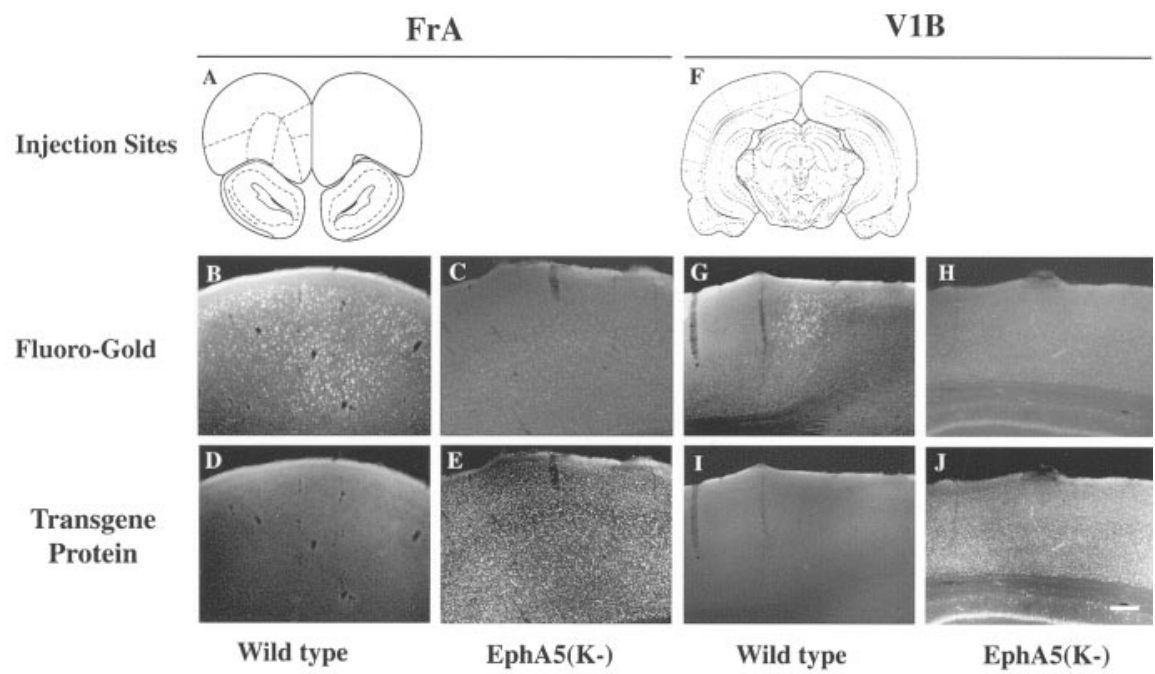

Figure 5. Callosal projection deficiency in frontal and visual areas of the transgenic mice. $A$, A diagram of a coronal section of the rostral mouse brain showing Fluoro-Gold injection site in the frontal association cortex (FrA). B, C, Retrograde labeling of contralateral frontal cortex in wild-type control $(B)$ and transgenic ( $C$ mice. $D, E$, Transgene protein expression in FrA area in wild-type $(D)$ and transgenic $(E)$ mice. $F$, A diagram of a coronal section of the mouse brain at the level of the primary visual cortex (V1B) showing the injection site. $G, H$, Retrograde labeling of contralateral visual cortex in wild-type $(G)$ and transgenic $(H)$ mice, respectively. I, J, Transgene protein expression in V1B area of wild-type ( $/$ ) and transgenic $(J)$ mice. Scale bar, $100 \mu \mathrm{m}$.

promoter on the development of corpus callosum in transgenic mice. The EphA5(K-) transgene contains the ligand-binding and transmembrane domains of EphA5 receptor but lacks the intracellular kinase domain. Kinase-null receptors serve as efficient inhibitors and interfere with normal functions of the endogenous receptors (Amaya et al., 1991; Ueno et al., 1991, 1992; Werner et al., 1994; Xu et al., 1995; Campochiaro et al., 1996; McFarlane et al., 1996; Xu et al., 1996). Previous analysis of these EphA5(K-) transgenic mice showed that hippocampal axons mistarget, with the medial axons terminating in the ventral lateral septum in-
S2

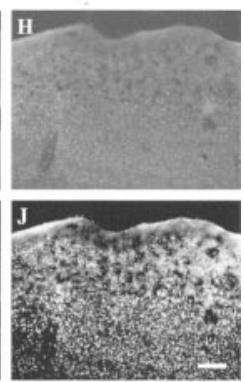

$\operatorname{EphA5(K-)}$ stead of their normal positions in the dorsal lateral septum (Yue et al., 2002). We show here that callosal axons in approximately half of the EphA5(K-) transgenic mice also exhibit failure to reach their contralateral targets. The incomplete penetrance could be caused by variations of the levels of transgene expression, which have been shown in our analysis (data not shown). The callosal defect was found in several brain regions examined and correlated with levels of transgene expression, indicating that the phenotype is caused specifically by the presence of the transgene. Consistent with these observations, EphA receptors are expressed in callosal neurons, and ephrin-A5 stimulates callosal neurite outgrowth in vitro. These studies indicate that the EphA receptors and their ligands, the A-ephrins, play critical roles in the development of callosal axon projection to their contralateral targets.

During development, callosal axons must make several pathfinding decisions to reach their contralateral targets. In the mouse, callosal axons originating from differentiated neurons in the cortical plate first extend radially downward to reach the cortical white matter around embryonic day 16. These axons then change their direction and travel toward the midline. On reaching the midline, the axons migrate over a mass of glial cells that bridge the two cerebral hemispheres and cross over to the contralateral side. Once the axons arrive at the contralateral cortex, they reenter the gray matter at specific positions according to the area of their origin (Innocenti, 1984) and form synapses with appropriate targets. The inability to cross the midline properly does not appear to affect the target specificity of callosal axons (Innocenti, 1984; Olavarria et al., 1988), indicating that crossing the midline and target selection in the contralateral cortex are independently regulated by distinct axon guidance molecules.

Because a large number of different syndromes ranging from brain degeneration to peripheral neuropathy are associated with callosal agenesis (Lassonde and Jeeves, 1994), callosal development is likely to be regulated by multiple factors. Mutations perturbing any of the guidance decisions, such as the initial growth of axons toward the white matter, axons turning medially, midline crossing, or the proper targeting in the contralateral cortex, could interfere with callosal development. Mouse mutations found in $\mathrm{BALB} / \mathrm{c}$ and related lines affect midline glial structures and prevent axons from crossing the midline (Wahlsten, 1989). In these mutants, callosal axons accumulate near the midline and project instead longitudinally on the ipsilateral side, forming Probst bundles. Similarly, mutations in a number of identified genes, includ- 


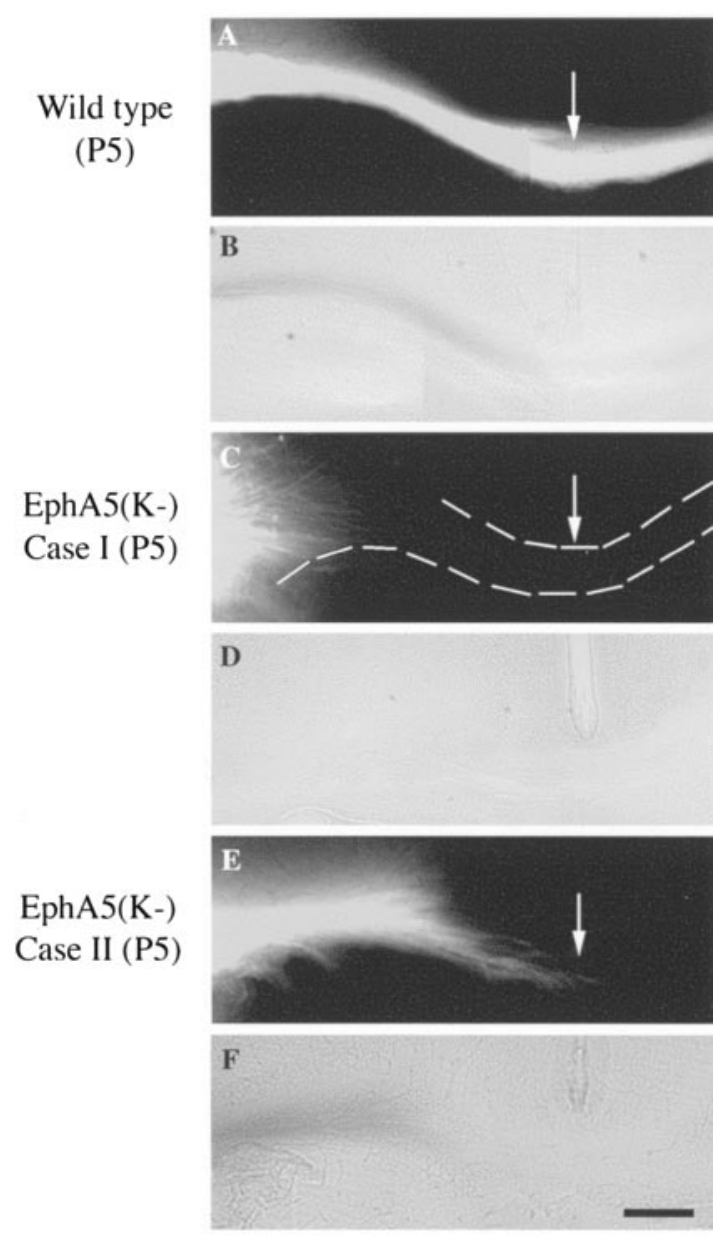

Figure 6. Analysis of callosal projections in developing (P5) mouse brains. Dil solutions were injected into the $\mathrm{S} 1$ area of $\mathrm{P} 5$ mice. $A, B$, Fluorescence $(A)$ and bright-field $(B)$ photomicrographs of callosal fibers in a wild-type control mouse. $C-F$, Fluorescence $(C, E)$ and bright-field $(D, F)$ photomicrographs of callosal fibers of two transgenic mice. Scale bar, $100 \mu \mathrm{m}$.
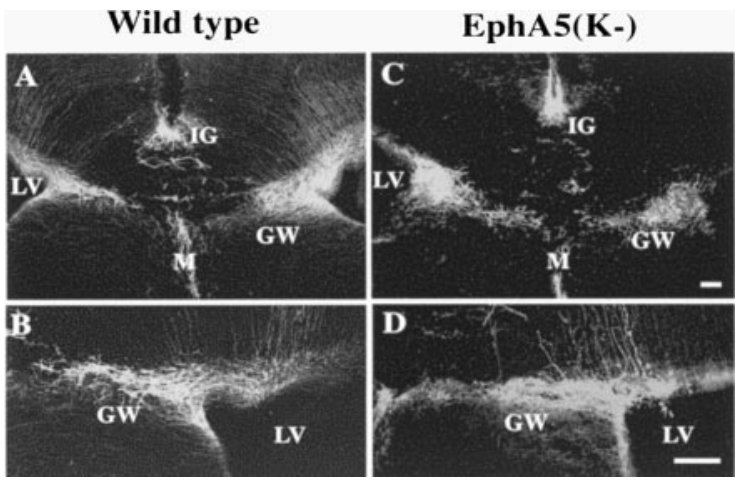

Figure 7. Midline glia structures are normal in developing transgenic mice. $A, B$, GFAPpositive cells at the midline of wild-type controls. C, D, GFAP-positive cells at the midline of the transgenic mice. $B$ and $D$ are higher magnification photomicrographs of the glial wedge in wild-type and transgenic mice, respectively. LV, Lateral ventricle; GW, glial wedge; IG, indusium griseum; M, midline. Scale bars, $100 \mu \mathrm{m}$.

ing the Eph family receptors EphB2 and EphB3, the homeobox gene Emx-1, and the axon guidance molecule netrin and its receptor deleted in colorectal cancer, also prevent midline axon crossing and induce the formation of Probst bundles (Orioli et al., 1996; Qiu et al., 1996; Serafini et al., 1996; Fazeli et al., 1997).
Thus, these genes are likely to regulate midline-crossing mechanisms.

In EphA5(K-) transgenic mice, two distinct phenotypes were observed. First, in the developing brain (P5), callosal axons fail to reach the callosal tract or the midline, indicating a retardation of axon growth or a lack of proper guidance toward the callosal tract. Second, in the adult, axons reaching the callosal axon track also fail to cross the midline and accumulate in the ipsilateral side forming Probst bundles. These observations indicate that the EphA receptors and ligands may have multiple functions in regulating callosal formation: in the initial growth and targeting of callosal axons toward the white matter and in midline crossing to the contralateral cerebral cortex. The defects in midline crossing are not likely to be caused by defects in midline glial structures, because callosal axons from the motor cortex do cross the midline and no gross morphological alterations of midline glial structures were observed. Although a role of the glial structures cannot be ruled out completely, the deficiency is most likely caused by inhibition of EphA receptor function in the callosal neurons, which interferes with the growth or guidance of callosal axons.

A function of the EphA receptors in callosal axon guidance is consistent with the expression of these receptors in callosal neurons. Previous studies from our laboratory and others have shown that many EphA receptors (EphA3-EphA7) are expressed in the developing cerebral cortex (Zhang et al., 1997; Donoghue and Rakic, 1999; Mackarehtschian et al., 1999). Several receptors, EphA3, EphA4, and EphA5, are expressed in layers 2/3 and 5 neurons during callosal axon targeting, consistent with roles in the development of callosal projections, because most of the callosal neurons reside in these layers. We have extended these earlier studies by using ephrin-A5-Fc affinity binding and specific antibodies and showed that callosal neurons express several EphA receptor proteins. In addition, it has been shown previously that EphA4 and EphA7 proteins were found in callosal fibers (Martone et al., 1997; Ciossek et al., 1999; Rogers et al., 1999). These observations together support the notion that the EphA receptors mediate guidance of callosal axons. Several A-ephrins, ligands of the EphA receptors, are also expressed in the developing cerebral cortex (Gao et al., 1998; Donoghue and Rakic, 1999; Mackarehtschian et al., 1999). Ephrin-A3 and ephrin-A4 are widely expressed in the developing cerebral cortex, whereas ephrin-A5 is expressed at high levels in the somatosensory cortex (Gao et al., 1998; Mackarehtschian et al., 1999). The presence of both receptors and ligands in the developing cortex suggests that the phenotypes observed here could be mediated by either of the following two mechanisms. First, the defects may be a result of inhibition of endogenous wild-type receptors. It has been shown previously that the EphA5(K-) transgene inhibits activation of the wild-type EphA receptors both in vitro and in vivo (Yue et al., 2002). This inhibition is likely mediated by heterodimerization between the truncated receptor and the wildtype EphA receptors, because Eph receptor heterodimerization has been shown to occur (Freywald et al., 2002). It is also possible that the truncated receptor inhibits endogenous receptor functions by competing for ligand binding. Second, the ectopically expressed EphA5 extracellular domain may activate ephrin-A ligands that in turn disrupt callosal axon pathfinding through reverse signaling. Both the $\mathrm{A}$ - and the $\mathrm{B}$-ephrins have been shown to possess the ability to signal after receptor binding (Cowan and Henkemeyer, 2002; Kullander and Klein, 2002). Because many axons fail to enter the callosal axon tract, the EphA-ephrin-A may function to guide callosal axons to the callosal white matter. Alternatively, the EphA-ephrin-A function may be required to 

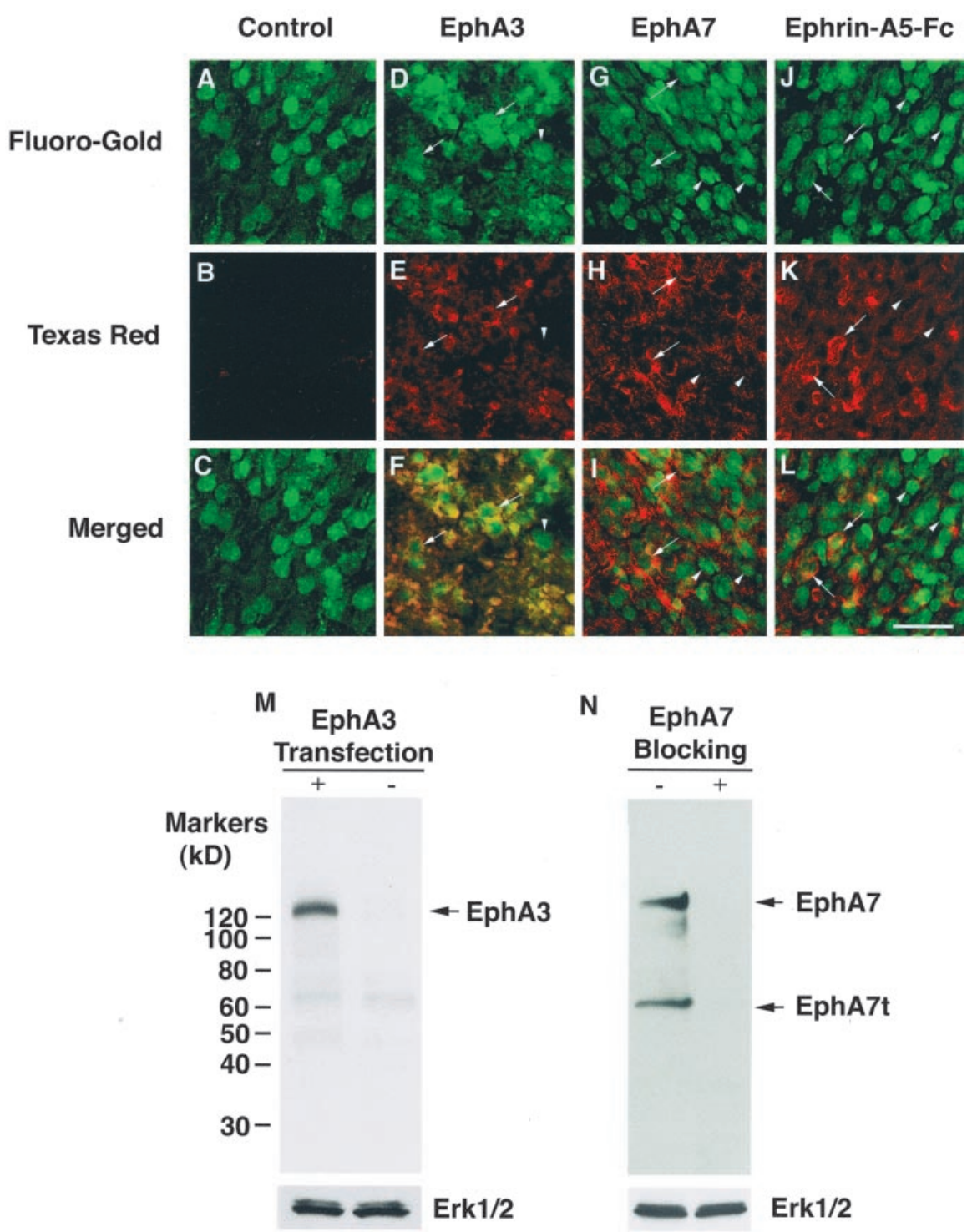

Figure 8. EphA receptors are expressed in callosal neurons. PO pups were injected with Fluoro-Gold unilaterally, and the contralateral cortices were processed and sectioned $2 \mathrm{~d}$ after injection. The sections were then examined for EphA receptor expression using select anti-EphA antibodies and ephrin-A5-Fc. The antibodies were detected with Texas-Red-conjugated secondary antibodies. Areas shown are from cortical layers where the densest callosal neurons were found. $A-C$, Immunostaining of a Fluoro-Gold-traced section with a preimmune rabbit serum. No specific staining was observed $(B) . D-F$, Immunostaining with anti-EphA3 antibody. G-I, Immunostaining with anti-EphA7 antibody. J-L, Immunostaining with ephrin-A5-Fc. A, D, G, J, Callosal neurons marked by Fluoro-Gold retrograde tracing. $B, E, H, K, I$, immunostaining with specific antibodies or ephrin-A5-Fc. $C, F, I, L$, Merged images of Fluoro-Gold-labeled callosal neurons and EphA receptor-positive neurons. Arrows indicate select receptorpositive callosal neurons. Arrowheads mark EphA receptor-negative callosal neurons. Scale bar, $50 \mu \mathrm{m}$. $M$, Specificity of the anti-EphA3 antibody. Control or EphA3-transfected human embryonic kidney (HEK) 293 cells were lysed, and $40 \mu \mathrm{g}$ of the cell lysates were analyzed using anti-EphA3 antibody. The blot was reprobed with anti-Erk $1 / 2$ antibody for protein-loading control. $N_{t}$ Specificity of the anti-EphA7 antibody. HEK293 cell lysate was analyzed with anti-EphA7 antibody in the absence (-) or presence $(+)$ of a blocking peptide. HEK293 cells express both a full-length (EphA7) and a truncated form (EphA7t) of EphA7 proteins.

stimulate axon outgrowth to reach the callosal axon tract. Indeed, we have shown that ephrin-A5 stimulates neurite outgrowth of callosal neurons. Earlier studies have indicated that the ephrins may stimulate cortical axon outgrowth and branching (Castellani et al., 1998; Zhou et al., 2001). The effects of ephrin-A5 are consistent with the presence of EphA3 and EphA7 in callosal neurons, because these receptors have been shown to have high affinity to ephrin-A5 (Janis et al., 1999). These observations suggest that EphA function is required for callosal axon growth toward the callosal tract, although a guidance function cannot be excluded.

Moderate enlargement of the lateral ventricles and reduction in cerebral cortical thickness were also observed in the EphA5(K-) transgenic mice (Fig. 2). Although it is not clear at present what is the cause of these phenotypes, they are consistent with reduced growth of cerebral cortical axons and dendrites. Because several EphA receptors are expressed in the cerebral cortex, expression of EphA5(K-) transgene may interfere with the growthpromoting functions of these receptors. Consistent with this view, ephirn-A5 promotes callosal axon growth in vitro (Fig. 9); however, degeneration of select neuronal populations is another possibility. It is possible that the transgene expression results in defects in axon targeting, which in turn leads to cell death. Further studies are necessary to clarify this issue.

In sum, studies reported here indicate that the EphA receptors and their ligands play critical roles in the development of the corpus callosum and may regulate callosal axon pathfinding at multiple-choice points.

\section{References}

Amaya E, Musci TJ, Kirschner MW (1991) Expression of a dominant negative mutant of the FGF receptor disrupts mesoderm formation in Xenopus embryos. Cell 66:257-270.

Campochiaro PA, Chang M, Ohsato M, Vinores SA, Nie Z, Hjelmeland L, Mansukhani A, Basilico C, Zack DJ (1996) Retinal degeneration in transgenic mice with photoreceptorspecific expression of a dominant-negative fibroblast growth factor receptor. J Neurosci 16:1679-1688.

Castellani V, Yue Y, Gao PP, Zhou R, Bolz J (1998) Dual action of a ligand for Eph receptor tyrosine kinases on specific populations of axons during the development of cortical circuits. J Neurosci 18:4663-4672.

Ciossek T, Ullrich A, West E, Rogers JH (1999) Segregation of the receptor EphA7 from its tyrosine kinase-negative isoform on neurons in adult mouse brain. Brain Res Mol Brain Res 74:231-236.

Cowan CA, Henkemeyer M (2002) Ephrins in reverse, park and drive. Trends Cell Biol 12:339-346.

Dodelet VC, Pasquale EB (2000) Eph receptors and ephrin ligands: embryogenesis to tumorigenesis. Oncogene 19:5614-5619.

Donoghue MJ, Rakic P (1999) Molecular evidence for the early specification of presumptive functional domains in the embryonic primate cerebral cortex. J Neurosci 19:5967-5979.

Fazeli A, Dickinson SL, Hermiston ML, Tighe RV, Steen RG, Small CG, Stoeckli ET, Keino-Masu K, Masu M, Rayburn H, Simons J, Bronson RT, Gordon JI, Tessier-Lavigne M, Weinberg RA (1997) Phenotype of mice lacking functional Deleted in colorectal cancer (Dcc) gene. Nature 386:796-804.

Flanagan JG, Vanderhaeghen P (1998) The ephrins and Eph receptors in neural development. Annu Rev Neurosci 21:309-345. 

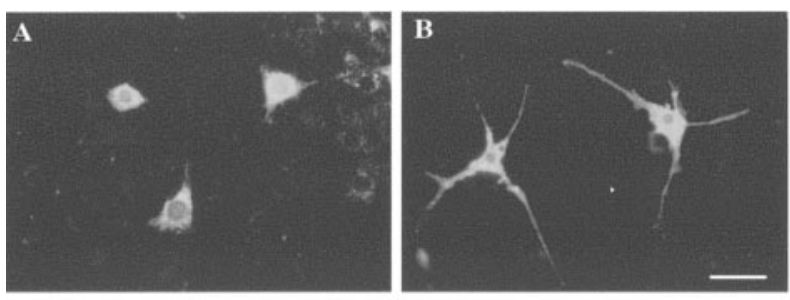

$\mathrm{C}$

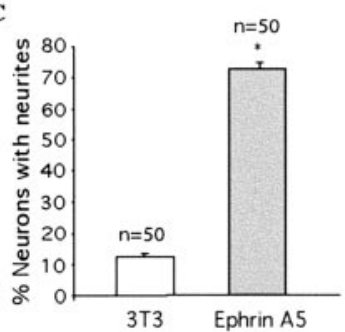

D

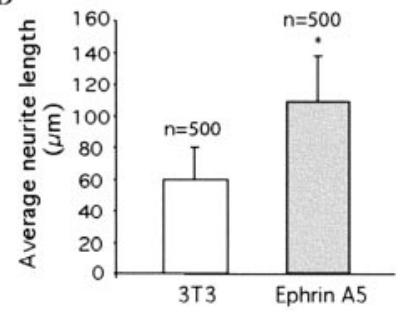

Figure 9. Ephrin-A5 stimulates neurite outgrowth of callosal neurons. Callosal neurons were marked by retrograde labeling with Dil injected into the contralateral cortex at P0. Cerebral cortical neurons were dissected and analyzed from the non-injected hemisphere $2 \mathrm{~d}$ after Dil injection. $A$, Callosal neurons cocultured with control NIH3T3 cells. Only short neurites were observed. B, Callosal neurons cocultured with NIH3T3 cells expressing ephrin-A5. C, Quantitative analysis of percentage of neurons with neurites when cocultured with control or ephrinA5-expressing cells. D, Average length of the neurites in cocultures with control and ephrin-A5expressing cells. ${ }^{*} p<0.05$; two-way ANOVA.

Franklin KBJ, Paxinos G (1997) The mouse brain. San Diego: Academic.

Freywald A, Sharfe N, Roifman CM (2002) The kinase-null EphB6 receptor undergoes transphosphorylation in a complex with EphB1. J Biol Chem 277:3823-3828.

Gao PP, Yue Y, Zhang JH, Cerretti DP, Levitt P, Zhou R (1998) Regulation of thalamic neurite outgrowth by the Eph ligand ephrin-A5: implications in the development of thalamocortical projections. Proc Natl Acad Sci USA 95:5329-5334.

Gao PP, Yue Y, Cerretti DP, Dreyfus C, Zhou R (1999) Ephrin-dependent growth and pruning of hippocampal axons. Proc Natl Acad Sci USA 96:4073-4077.

Gazzaniga MS (1995) Principles of human brain organization derived from split-brain studies. Neuron 14:217-228.

Henkemeyer M, Orioli D, Henderson JT, Saxton TM, Roder J, Pawson T, Klein R (1996) Nuk controls pathfinding of commissural axons in the mammalian central nervous system. Cell 86:35-46.

Innocenti GM (1984) General organization of callosal connections in the cerebral cortex. In: Cerebral cortex, pp 291-353. New York: Plenum.

Janis LS, Cassidy RM, Kromer LF (1999) Ephrin-A binding and EphA receptor expression delineate the matrix compartment of the striatum. J Neurosci 19:4962-4971.

Kullander K, Klein R (2002) Mechanisms and functions of Eph and ephrin signalling. Nat Rev Mol Cell Biol 3:475-486.

Lassonde M, Jeeves MA, ed (1994) Callosal agenesis: a natural split brain. New York: Plenum.

Mackarehtschian K, Lau CK, Caras I, McConnell SK (1999) Regional differences in the developing cerebral cortex revealed by ephrin-A5 expression. Cereb Cortex 9:601-610.

Martone ME, Holash JA, Bayardo A, Pasquale EB, Ellisman MH (1997) Immunolocalization of the receptor tyrosine kinase EphA4 in the adult rat central nervous system. Brain Res 771:238-250.

McFarlane S, Cornel E, Amaya E, Holt CE (1996) Inhibition of FGF receptor activity in retinal ganglion cell axons causes errors in target recognition. Neuron 17:245-254.
Mori T, Wanaka A, Taguchi A, Matsumoto K, Tohyama M (1995) Localization of novel receptor tyrosine kinase genes of the eph family, MDK1 and its splicing variant, in the developing mouse nervous system. Brain Res Mol Brain Res 34:154-160.

Olavarria J, Serra-Oller MM, Yee KT, Van Sluyters RC (1988) Topography of interhemispheric connections in neocortex of mice with congenital deficiencies of the callosal commissure. J Comp Neurol 270:575-590.

Orioli D, Henkemeyer M, Lemke G, Klein R, Pawson T (1996) Sek4 and Nuk receptors cooperate in guidance of commissural axons and in palate formation. EMBO J 15:6035-6049.

Qiu M, Anderson S, Chen S, Meneses JJ, Hevner R, Kuwana E, Pedersen RA, Rubenstein JL (1996) Mutation of the Emx-1 homeobox gene disrupts the corpus callosum. Dev Biol 178:174-178.

Rogers JH, Ciossek T, Ullrich A, West E, Hoare M, Muir EM (1999) Distribution of the receptor EphA7 and its ligands in development of the mouse nervous system. Brain Res Mol Brain Res 74:225-230.

Serafini T, Colamarino SA, Leonardo ED, Wang H, Beddington R, Skarnes WC, Tessier-Lavigne M (1996) Netrin-1 is required for commissural axon guidance in the developing vertebrate nervous system. Cell 87:1001-1014.

Shu T, Richards LJ (2001) Cortical axon guidance by the glial wedge during the development of the corpus callosum. J Neurosci 21:2749-2758.

Sperry R (1982) Some effects of disconnecting the cerebral hemispheres. Science 217:1223-1226.

Sperry RW (1968) Hemisphere deconnection and unity in conscious awareness. Am Psychol 23:723-733.

Taylor V, Miescher GC, Pfarr S, Honegger P, Breitschopf H, Lassmann H, Steck AJ (1994) Expression and developmental regulation of Ehk-1, a neuronal Elk-like receptor tyrosine kinase in brain. Neuroscience 63:163-178.

Ueno H, Colbert H, Escobedo JA, Williams LT (1991) Inhibition of PDGF beta receptor signal transduction by coexpression of a truncated receptor. Science 252:844-848.

Ueno H, Gunn M, Dell K, Tseng A Jr, Williams L (1992) A truncated form of fibroblast growth factor receptor 1 inhibits signal transduction by multiple types of fibroblast growth factor receptor. J Biol Chem 267:1470-1476.

Wahlsten D (1989) Deficiency of the corpus callosum: incomplete penetrance and substrain differentiation in BALB/c mice. J Neurogenet 5:61-76.

Werner S, Smola H, Liao X, Longaker MT, Krieg T, Hofschneider PH, Williams LT (1994) The function of KGF in morphogenesis of epithelium and reepithelialization of wounds. Science 266:819-822.

Wilkinson DG (2000) Eph receptors and ephrins: regulators of guidance and assembly. Int Rev Cytol 196:177-244.

Xu Q, Alldus G, Holder N, Wilkinson DG (1995) Expression of truncated Sek-1 receptor tyrosine kinase disrupts the segmental restriction of gene expression in the Xenopus and zebrafish hindbrain. Development 121:4005-4016.

Xu Q, Alldus G, Macdonald R, Wilkinson DG, Holder N (1996) Function of the Eph-related kinase rtk1 in patterning of the zebrafish forebrain. Nature 381:319-322.

Yue Y, Chen ZY, Gale NW, Blair-Flynn J, Hu TJ, Yue X, Cooper M, Crockett DP, Yancopoulos GD, Tessarollo L, Zhou R (2002) Mistargeting hippocampal axons by expression of a truncated Eph receptor. Proc Natl Acad Sci USA 99:10777-10782.

Zhang JH, Pimenta AF, Levitt P, Zhou R (1997) Dynamic expression suggests multiple roles of the eph family receptor brain-specific kinase (Bsk) during mouse neurogenesis. Brain Res Mol Brain Res 47:202-214.

Zhou R (1998) The Eph family receptors and ligands. Pharmacol Ther 77:151-181.

Zhou X, Suh J, Cerretti DP, Zhou R, DiCicco-Bloom E (2001) Ephrins stimulate neurite outgrowth during early cortical neurogenesis. J Neurosci Res 66:1054-1063. 